\title{
(6) OPEN ACCESS \\ A randomised, double-blind, phase III study comparing SB2, an infliximab biosimilar, to the infliximab reference product Remicade in patients with moderate to severe rheumatoid arthritis despite methotrexate therapy
}

\author{
Jung-Yoon Choe, ${ }^{1}$ Nenad Prodanovic, ${ }^{2}$ Jaroslaw Niebrzydowski, ${ }^{3}$ Ivan Staykov, ${ }^{4}$ \\ Eva Dokoupilova, ${ }^{5}$ Asta Baranauskaite, ${ }^{6}$ Roman Yatsyshyn, ${ }^{7}$ Mevludin Mekic, ${ }^{8}$ \\ Wieskawa Porawska, ${ }^{9}$ Hana Ciferska ${ }_{1}^{10}$ Krystyna Jedrychowicz-Rosiak, ${ }^{11}$ \\ Agnieszka Zielinska, ${ }^{12}$ Jasmine Choi, ${ }^{13}$ Young Hee Rho, ${ }^{13}$ Josef S Smolen ${ }^{14}$
}

\begin{abstract}
Handling editor Tore K Kvien
- Additional material is published online only. To view please visit the journal online (http://dx.doi.org/10.1136/ annrheumdis-2015-207764)
\end{abstract}

For numbered affiliations see end of article.

\section{Correspondence to} Professor Josef S Smolen, Division of Rheumatology, Department of Medicine 3, Medical University of Vienna, Waehringer Guertel 18-20, Vienna A-1090, Austria; josef.smolen@wienkav.at

A portion of the manuscript was presented as an abstract (SAT0152) at Rome in EULAR 2015.

Received 10 April 2015 Revised 7 August 2015 Accepted 12 August 2015 Published Online First 28 August 2015

\section{SLinked}

- http://dx.doi.org/10.1136/ annrheumdis-2015-207588 - http://dx.doi.org/10.1136/ annrheumdis-2015-207613 - http://dx.doi.org/10.1136/ annrheumdis-2015-208113

To cite: Choe J-Y

Prodanovic N,

Niebrzydowski J, et al. Ann

Rheum Dis 2017;76:58-64.

\section{ABSTRACT}

Objectives To compare the efficacy, safety, immunogenicity and pharmacokinetics (PK) of SB2 to the infliximab reference product (INF) in patients with moderate to severe rheumatoid arthritis (RA) despite methotrexate therapy.

Methods This is a phase III, randomised, double-blind, multinational, multicentre parallel group study. Patients with moderate to severe RA despite methotrexate therapy were randomised in a 1:1 ratio to receive either SB2 or INF of $3 \mathrm{mg} / \mathrm{kg}$. The primary end point was the American College of Rheumatology 20\% (ACR20) response at week 30. Inclusion of the $95 \% \mathrm{Cl}$ of the ACR20 response difference within a $\pm 15 \%$ margin was required for equivalence.

Results 584 subjects were randomised into SB2 $(\mathrm{N}=291 ; 290$ analysed) or INF ( $\mathrm{N}=293)$. The ACR20 response at week 30 in the per-protocol set was $64.1 \%$ in SB2 versus $66.0 \%$ in INF. The adjusted rate difference was $-1.88 \%(95 \% \mathrm{Cl}-10.26 \%$ to $6.51 \%)$, which was within the predefined equivalence margin. Other efficacy outcomes such as ACR50/70, disease activity score measured by 28 joints and European League against Rheumatism response were similar between SB2 and INF. The incidence of treatment-emergent adverse events was comparable (57.6\% in SB2 vs $58.0 \%$ in INF) as well as the incidence of antidrug antibodies (ADA) to infliximab up to week $30(55.1 \%$ in SB2 vs $49.7 \%$ in INF). The PK profile was similar between SB2 and INF. Efficacy, safety and PK by ADA subgroup were comparable between SB2 and INF.

Conclusions SB2 was equivalent to INF in terms of ACR20 response at week 30. SB2 was well tolerated with a comparable safety profile, immunogenicity and PK to INF.

Trial registration number NCT01936181.

\section{INTRODUCTION}

Rheumatoid arthritis (RA) is a chronic autoimmune inflammatory disease that leads to morbidity resulting in high societal costs. ${ }^{12}$ While disease modifying antirheumatic drugs such as methotrexate (MTX) have significantly improved the outcome in
RA, not all patients respond. ${ }^{3}$ The advent of biological agents including tumour necrosis factor (TNF) inhibitors has revolutionised the treatment of $\mathrm{RA} ;{ }^{3}{ }^{4}$ however the high cost is a significant burden to the patient and society.

A biosimilar is a biologic agent that contains a (similar) version of the active substance of an already authorised original biological medicinal (reference) product. ${ }^{6}$ Due to the complexity of the manufacturing process, biosimilars differ from generic drugs in the chemical drug area. ${ }^{6} 7$ Thus, the approval pathway of biosimilars is different from generics; very roughly three major steps are employed. ${ }^{8}$ First, a comprehensive physicochemical and biological characterisation ${ }^{6}$ is done to prove similarity on the molecular level (including in vivo and in vitro assays), second, a pharmacokinetic (PK) study is done to show bioequivalence, and finally, an efficacy study (usually a randomised controlled study) is done to demonstrate clinical equivalence, compared with the reference product. The development of Remsima (code name CT-P13, Celltrion, Incheon, Korea), a biosimilar of infliximab (Remicade, Janssen Biotech, Horsham, Pennsylvania, USA), has followed this process ${ }^{9-11}$ and recently been approved by the European Medicines Agency. ${ }^{12}$ The development of biosimilars is anticipated to greatly decrease the economic burden of biological therapy. ${ }^{13}$

SB2 is developed as a biosimilar of infliximab. SB2 has undergone the stepwise process described above; SB2 was shown to be similar on the molecular level and bioequivalent in normal human subjects in a phase I PK study, ${ }^{14}$ all compared with the infliximab reference product (INF). This study now reports the primary results of the phase III studyto demonstrate clinical equivalence in patients with moderate to severe RA despite MTX treatment, compared with INF.

\section{PATIENTS AND METHODS}

\section{Patients}

Patients who were 18-75 years old with RA classified by the 1987 American College of 
Rheumatology (ACR) classification criteria for RA were enrolled; patients had to have had RA for at least 6 months with least six tender joints and six swollen joints; an erythrocyte sedimentation rate (ESR) of $\geq 28 \mathrm{~mm} / \mathrm{h}$ or a $\mathrm{C}$ reactive protein of $\geq 1.0 \mathrm{mg} / \mathrm{dL}$ was required. Patients had to take MTX for at least 6 months and had to be under a stable dose for at least 4 weeks before randomisation. For details of inclusion and exclusion criteria, see online supplementary appendix S1.

\section{Study design}

This study is a phase III, randomised, double-blind, multinational, multicentre parallel group study (NCT01936181, EudraCT 2012-005733-37). The study consists of a 54-week main study and an additional 24-week transition (switching) study; this report is about the results of the 54-week main study up to week 30 (for the graphical presentation see online supplementary appendix S2-1), which includes the primary outcome. Patients were randomised in a 1:1 ratio to receive either SB2 or INF of $3 \mathrm{mg} / \mathrm{kg}$ intravenously. Randomisation and treatment allocation was implemented through an interactive web responsive system (Cenduit LLC, see online supplementary appendix S3-1). Infusion of SB2 or INF was done over $2 \mathrm{~h}$; dosing was done at each visit at week 0 , week 2 , week 6 , week 14 , week 22, week 30, week 38 and week 46. Dose increases could occur from week 30 by $1.5 \mathrm{mg} / \mathrm{kg}$ per visit, up to a total of $7.5 \mathrm{mg} / \mathrm{kg}$. The final visit for the main study occurred at week 54. To prevent infusion related reactions (IRRs), premedications such as corticosteroids, antihistamines or paracetamol were allowed per investigator discretion. MTX was given as an oral or parenteral weekly dose of 10-25 mg/week with folic acid of 5-10 mg/ week. Non-steroidal anti-inflammatory drugs and corticosteroids ( $\leq 10 \mathrm{mg}$ prednisolone) were allowed if taken for a stable dose for 4 weeks before randomisation. Other disease modifying antirheumatic drugs except for MTX were prohibited during the study. All patients were screened for tuberculosis (TB) by medical history, chest X-ray and QuantiFERON-TB Gold In-Tube tests (Qiagen); QuantiFERON tests were done at screening, week 22 and week 54. Patients with active TB were ineligible for the study and those who were found to have latent TB had to undergo prophylaxis according to country-specific guidelines to enrol in or continue with the study. The study was conducted in 73 centres in 11 countries from Europe and Asia. The study was conducted according to the Declaration of Helsinki and Good Clinical Practice issued by the International Committee on Harmonisation. All patients gave formal written informed consent before participating in the study.

\section{Assessments}

Efficacy, safety and immunogenicity assessments for all patients were done at each visit before SB2 or INF infusion.

The primary end point of the study was the ACR 20\% (ACR20) response at week 30 in the per-protocol set (PPS). Other secondary efficacy end points included ACR50 and ACR70, disease activity score measured by 28 joints-erythrocyte sedimentation rate (DAS28-ESR) and European League against Rheumatism (EULAR) response. A post hoc analysis of simplified disease activity index (SDAI) and clinical disease activity index (CDAI) was done to measure the proportion of patients achieving low disease activity (LDA) or remission. ${ }^{15} 16$ Efficacy components such as tender and swollen joint counts, visual analogue scales scores and health assessment questionnaire of disability index scores were assessed before each infusion.

Safety assessments included monitoring of vital signs, physical examination, laboratory assessments and reports of adverse events (AEs). AEs were collected in particular for serious AEs, serious infections or TB and IRRs.

Immunogenicity assessments were done by measuring serum antidrug antibodies (ADAs) to infliximab at each visit before infusion. ADA-positivity was defined as those who had at least one positive ADA result up to week 30 . This was a prespecified outcome, according to recommendations from the American Association of Pharmaceutical Scientists. ${ }^{17}$ It accommodates all measures of ADA incidence over each individual time point that may be subject to variation. Those who were ADA-positive were additionally assessed for neutralising antibodies. A single-assay approach with a SB2 tag was used to assess immunogenicity. ADAs were measured using validated electrochemiluminescence immunoassays and neutralising antibodies were measured using a competitive ligand-binding assay (MesoScale Discovery platform, Meso Scale Discovery, Rockville, Maryland, USA).

$\mathrm{PK}$ assessments were done by measuring the serum trough concentrations $\left(\mathrm{C}_{\text {trough }}\right)$ of infliximab before each infusion. Serum infliximab concentrations were determined using a validated ELISA.

\section{Sample size and statistical analysis}

The primary objective was to demonstrate equivalence of ACR2 0 at week 30. To determine equivalence between SB2 and INF the $95 \%$ CI of the ACR20 rate difference had to be within the prespecified margin of $-15 \%$ and $+15 \%$. The equivalence margin was determined using data from several INF studies $^{4} 1819$ and regulatory guidelines. ${ }^{20} 21$ Sample size was calculated assuming this equivalence margin of $\pm 15 \%$, an effect size of $57 \%$ and a $20 \%$ dropout rate. With a significance level of $5 \%$ and a power of $80 \%$, a sample size of at least 292 randomised patients per treatment group was required in order to reach the required subject size for the PPS.

The primary efficacy outcome was analysed using the PPS and the full analysis set (FAS). ${ }^{22}$ FAS follows the same principles of the intention-to-treat analysis; FAS included all randomised patients who received at least one dose of SB2 or INF. In addition, if missing data occurred, such patients were assumed to be ACR20 non-responders in FAS. For analysis of ACR20, the rate difference was adjusted by baseline $C$ reactive protein and geographical region using a non-parametrical analysis of covariance. $^{23-25}$ Analysis of ACR50 and ACR70 was also done in PPS and FAS; DAS28, SDAI, CDAI and EULAR response were done only in the FAS (only available DAS28 and SDAI/CDAI were analysed in this case). Subgroup analysis of ACR20 was done by comparing ACR20 response rates within each ADA subgroup (positive or negative) in a prespecified manner. To formally test the differential influence of ADA on SB2 or INF, an analysis of covariance was done including an ADA-by-treatment interaction term in the model.

A prespecified exponential time-response model using nonlinear mixed models ${ }^{26}$ was fitted to compare the ACR20 response between SB2 and INF over time (see also online supplementary appendix S3-2). The squared differences across all time points from the two curves (2-norm) were measured, and if the upper limit of the $95 \%$ CI of the 2-norm was less than 61.80 , the two curves were considered equivalent.

Safety results were presented as the number of patients with percentage who had a particular AE in the safety analysis set (SAF; those who received at least one dose of SB2 or INF). Immunogenicity results were presented as the number of patients with percentages having incident ADA up to week 30 from the SAF. PK assessment was done in the PK population (approximately the first enrolled $50 \%$ of the study population) 
up to week 30 . PK results are shown as mean $C_{\text {trough }}$ with SD and coefficient of variation from the PK population.

General statistical analysis was done using SAS V.9.2 (SAS, Cary, North Carolina, USA). PK parameters were calculated by non-compartmental analyses (WinNonlin V.5.2, Pharsight, Mountain View, California, USA). Graphical figures were made using R 3.0.1 (http://www.r-project.org).

\section{RESULTS}

\section{Patients}

The study was conducted from August 2013, and the results presented in this report are from data that were collected up to mid-November 2014. The median follow-up period was 296 days. This data set included all patients that completed the week 30 visit. Among 805 patients screened, 584 patients were randomised (SB2, $\mathrm{N}=291$ and $\mathrm{INF}, \mathrm{N}=293$, figure 1). From the SB2 treatment group, one patient was found to be ineligible after randomisation and withdrew before the first infusion. The baseline characteristics of the study population are shown in table 1; the two treatment groups were well-balanced. Two hundred and forty-six patients from the SB2 treatment group and 259 patients from the INF treatment group completed the week 30 visit; the most common reason for withdrawal was due to AEs and withdrawal of consent (figure 1). Among those who completed week 30, 15 patients (5.2\%) from SB2 and 12 patients $(4.1 \%)$ from INF were excluded from the PPS due to protocol deviations (see online supplementary appendix S4-3).

\section{Efficacy}

The primary efficacy end point ACR20 at week 30 is shown in figure 2. The ACR20 for the PPS was $64.1 \%$ for SB2 and $66.0 \%$ for INF. The $95 \%$ CI for the rate difference was $-10.26 \%$ to $6.51 \%$, which was within the prespecified equivalence margin of $\pm 15 \%$. This was also similarly shown in the FAS; ACR20 was $55.5 \%$ for SB2 and $59.0 \%$ for INF, with the $95 \%$ CI $-10.88 \%$ to $4.97 \%$. Thus, the equivalence of SB2 compared with INF was concluded (for unadjusted analyses, see online supplementary appendix S4-1). Other efficacy outcomes

\begin{tabular}{|c|c|c|c|}
\hline & $\begin{array}{l}\text { SB2 } \\
(N=291)\end{array}$ & $\begin{array}{l}\text { INF } \\
(N=293)\end{array}$ & $\begin{array}{l}\text { Total } \\
(\mathrm{N}=584)\end{array}$ \\
\hline Age (years) & $51.6 \pm 11.9$ & $52.6 \pm 11.7$ & $52.1 \pm 11.8$ \\
\hline Gender (female) & $79.7 \%$ & $80.5 \%$ & $80.1 \%$ \\
\hline Race (white) & $86.6 \%$ & $86.7 \%$ & $86.6 \%$ \\
\hline Height $(\mathrm{cm})$ & $164.6 \pm 9.3$ & $164.8 \pm 8.6$ & $164.7 \pm 8.9$ \\
\hline Weight (kg) & $72.3 \pm 15.8$ & $71.9 \pm 16.5$ & $72.1 \pm 16.2$ \\
\hline BMI $\left(\mathrm{kg} / \mathrm{m}^{2}\right)$ & $26.6 \pm 5.3$ & $26.5 \pm 6.0$ & $26.6 \pm 5.6$ \\
\hline Disease duration (years) & $6.3 \pm 5.9$ & $6.6 \pm 6.0$ & $6.4 \pm 5.9$ \\
\hline Rheumatoid factor & $73.9 \%$ & $71.0 \%$ & $72.4 \%$ \\
\hline Tender joint count (68 joint) & $23.6 \pm 12.3$ & $24.0 \pm 12.2$ & $23.8 \pm 12.3$ \\
\hline Swollen joint count (66 joint) & $14.6 \pm 7.8$ & $14.9 \pm 7.7$ & $14.7 \pm 7.8$ \\
\hline $\begin{array}{l}\text { Duration of methotrexate therapy } \\
\text { (months) }\end{array}$ & $53.5 \pm 49.9$ & $48.2 \pm 45.5$ & $50.8 \pm 47.8$ \\
\hline Methotrexate dose (mg/week) & $14.7 \pm 4.2$ & $14.7 \pm 4.1$ & $14.7 \pm 4.2$ \\
\hline $\mathrm{CRP}(\mathrm{mg} / \mathrm{L})$ & $12.5 \pm 18.8$ & $13.7 \pm 19.2$ & $13.1 \pm 19.0$ \\
\hline $\mathrm{ESR}(\mathrm{mm} / \mathrm{h})$ & $44.5 \pm 19.2$ & $46.7 \pm 22.3$ & $45.6 \pm 20.9$ \\
\hline HAQ-DI & $1.5 \pm 0.6$ & $1.5 \pm 0.6$ & $1.5 \pm 0.6$ \\
\hline Pain VAS (mm) & $61.2 \pm 18.6$ & $63.3 \pm 20.0$ & $62.3 \pm 19.3$ \\
\hline Subject GA, VAS (mm) & $62.9 \pm 17.5$ & $62.7 \pm 18.7$ & $62.8 \pm 18.1$ \\
\hline Physician GA, VAS (mm) & $61.7 \pm 15.5$ & $61.8 \pm 15.8$ & $61.7 \pm 15.7$ \\
\hline DAS28-ESR & $6.5 \pm 0.8$ & $6.5 \pm 0.8$ & $6.5 \pm 0.8$ \\
\hline SDAl & $39.3 \pm 11.9$ & $40.1 \pm 11.8$ & $39.7 \pm 11.8$ \\
\hline CDAI & $38.3 \pm 12.6$ & $38.7 \pm 11.4$ & $38.5 \pm 12.0$ \\
\hline
\end{tabular}

Data are presented in either mean \pm SD or percentage (\%).

$\mathrm{BMI}$, body mass index; CDAl, clinical disease activity index; CRP, $C$ reactive protein; DAS28, disease activity score measured by 28 joints; ESR, erythrocyte sedimentation rate; GA, global assessment of disease activity; HAQ-DI, health assessment questionnaire of disability index; INF, infliximab reference product; SDAI, simplified disease activity index; VAS, visual analogue scale.

such as ACR50 or ACR70 were also similar in the PPS and FAS (figure 2). Finally, the ACR20 response over time is shown in figure 3. The ACR20 response at each visit was similar between SB2 and INF; the two time-response curves were determined to be equivalent.

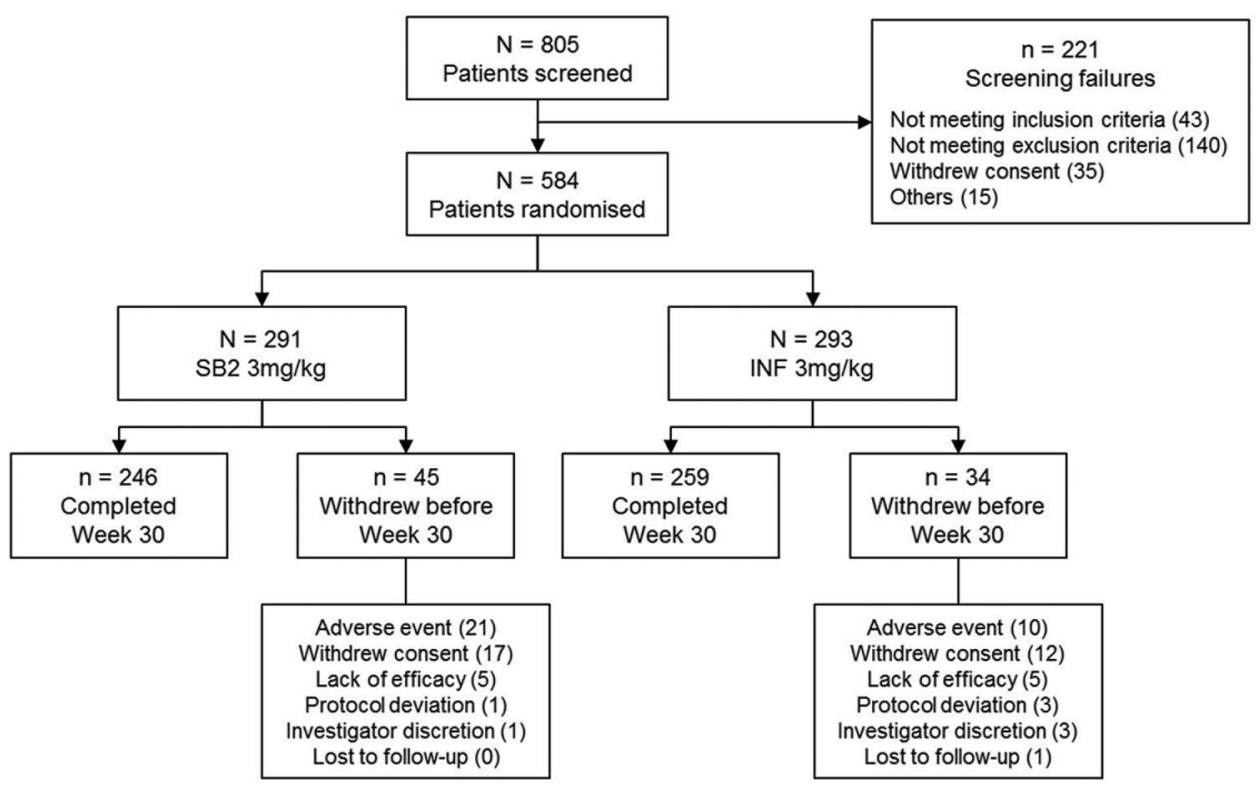

Figure 1 Disposition flow chart of the study population. Among the 584 randomised, one patient from the SB2 treatment group withdrew before taking the first dose of SB2. Accordingly, the full analysis set (FAS) for SB2 is N=290 and infliximab reference product (INF) N=293 (same with the safety population (SAF)). The per-protocol set (PPS) for SB2 is $N=231$ and INF N=247. The pharmacokinetics population for SB2 is $N=165$ and INF $\mathrm{N}=160$ (approximately $50 \%$ of the FAS). 
A

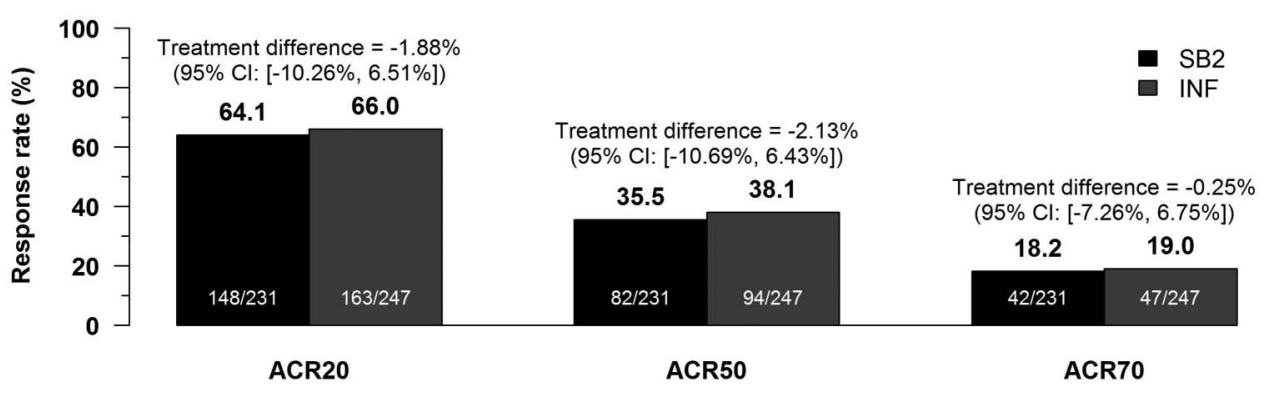

B

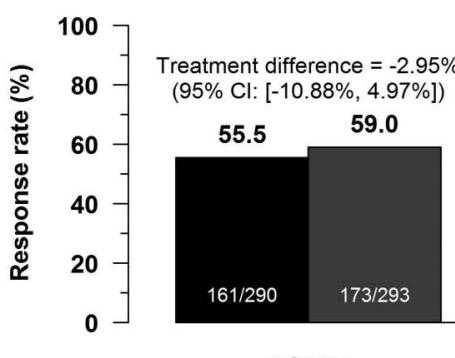

(FAS)

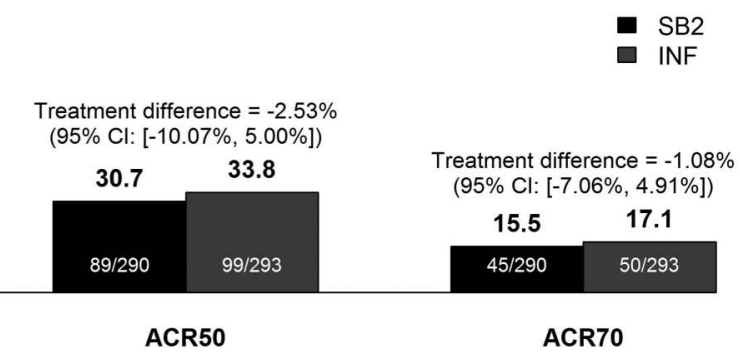

ACR50

Figure 2 American College of Rheumatology (ACR) response rates at week 30. (A) ACR20, 50 and 70 responses for SB2 and infliximab reference product (INF) in the per-protocol set (PPS). (B) ACR20, 50 and 70 responses for SB2 and INF in the full analysis set (FAS). Rate differences were calculated by non-parametrical analysis of covariance adjusted for baseline $\mathrm{C}$ reactive protein and region.

The changes of each efficacy component used for calculating ACR responses or DAS28 activity from baseline to week 30 were similar between SB2 and INF (see online supplementary appendix S4-2). The overall ACR20 response rate was lower in the ADA-positive subgroup compared with the ADA-negative subgroup, but was also similar between SB2 and INF within each ADA subgroup $(73.1 \%$ vs $73.6 \%$, ADA-negative subgroup; $56.7 \%$ vs $58.7 \%$, ADA-positive subgroup, see online supplementary appendix S4-3), and the interaction of ADA status by treatment group was not significant $(p=0.989)$.

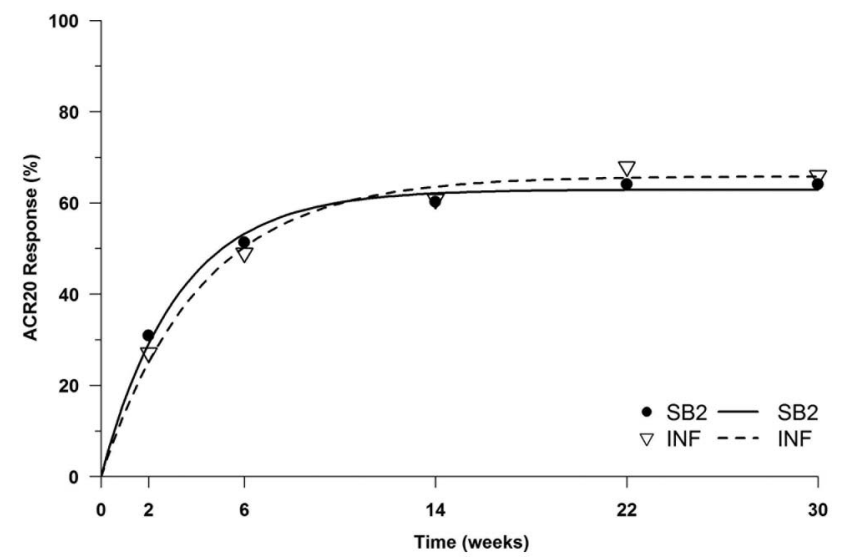

Figure 3 ACR20 response pattern over time. Dots are actual ACR20 response rates for SB2 and infliximab reference product (INF) at each visit (per-protocol set, PPS) and the curve is fitted by non-linear mixed models employing an exponential time-response model. The upper limit of the $95 \% \mathrm{Cl}$ for the 2-norm was 35.8 , which was below the prespecified equivalence margin of 61.8. For details about determining equivalence between the two time-response curves, please refer to the text.
The response for DAS28 over time, the proportion of LDA/ remission by DAS28, SDAI and CDAI are shown in figure 4. The improvement of DAS28 over time at each visit was similar between SB2 and INF (figure 4A), and the proportion of LDA was $11.1 \%$ for SB2 and $9.8 \%$ for INF (DAS28) and $33.3 \%$ vs $30.2 \%$ (SDAI), and for remission it was $14.6 \%$ vs $15.9 \%$ for DAS28 and $9.5 \%$ vs $10.9 \%$ for SDAI (figure 4B, C). The proportion of EULAR response was also similar between SB2 and INF (see online supplementary appendix S4-4). Overall, the efficacy end points were equivalent or similar between SB2 and INF.

\section{Safety}

During the study period 499 treatment-emergent AEs (TEAEs) occurred in 167 patients (57.6\%) in the SB2 treatment group and 529 TEAEs occurred in 170 patients $(58.0 \%)$ in the INF treatment group (table 2). The most common TEAEs that occurred were latent $\mathrm{TB}$, increased alanine aminotransferase (ALT) levels and headache. Most of the TEAEs were mild to moderate in severity. The proportion of TEAEs reported as related to the study drug was low (SB2 $21.4 \%$ vs INF $20.1 \%$ ). Most of the patients with treatment-emergent latent TB underwent $\mathrm{TB}$ prophylaxis and none of them developed TB.

Among the TEAEs, $9.0 \%$ from SB2 and $8.9 \%$ from INF reported at least one serious AE. There were nine patients (3.1\%) from SB2 who developed a serious infection or TB compared with six (2.0\%) patients in the INF treatment group (incidence rate: 4.1 cases/ 100 person-years for SB2 and 2.7 cases/ 100 person-years for INF), and one event in each treatment group was active TB (table 2). None of the active TB cases were found to have latent TB at screening. No serious cases of opportunistic infections were reported. There were 28 patients $(4.8 \%)$ who developed an IRR; 15 (5.2\%) from SB2 and 13 (4.4\%) from INF reported an IRR. The number of patients who 

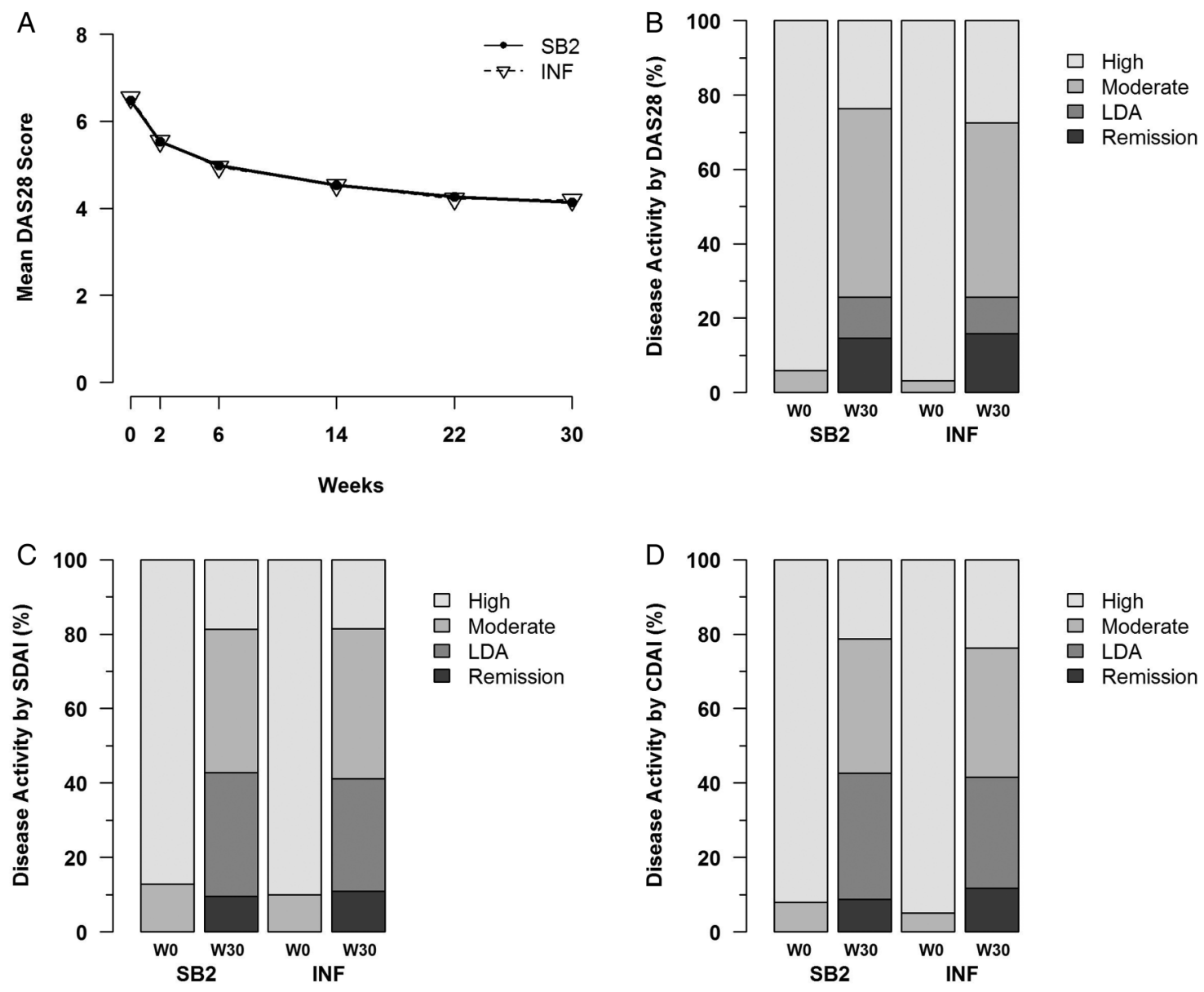

Figure 4 DAS28, SDAI and CDAI responses. (A) Mean DAS28 scores by visit for SB2 and infliximab reference product (INF). (B-D) Disease activity classification by DAS28, SDAI and CDAl. Remission is defined as DAS28<2.6, SDAI $\leq 3.3$ or CDAI $\leq 2.8$ and LDA is defined as DAS28 $2.6 \leq$ to $<3.2$, SDAI $3.3<$ to $\leq 11.0$ or CDAI $2.8<$ to $\leq 10.0$. DAS28, disease activity score measured by 28 joints; SDAl, simplified disease activity index; CDAl, clinical disease activity index; LDA, low disease activity.

developed IRRs by ADA status were 13 (4.5\%) for SB2 and 9 (3.1\%) for INF in the ADA-positive subgroup and $2(0.7 \%)$ and $4(1.4 \%)$ in the ADA-negative subgroup. There were no reported cases of delayed hypersensitivity or serum sickness. There were two cases of malignancies from SB2 (prostate cancer and breast cancer) and one case of heart failure from INF, which was also the only case of death. Overall, the safety profile was comparable between SB2 and INF.

\section{Immunogenicity and PKs}

Patients who developed ADA up to week 30 were 55.1\% (158/ $287)$ in the SB2 treatment group and $49.7 \%(145 / 292)$ in the INF treatment group, which difference was not statistically significant $(\mathrm{p}=0.212)$.

The PK results from the PK population are shown in online supplementary appendix S5. Overall, the $\mathrm{C}_{\text {trough }}$ of infliximab was similar between SB2 and INF over time and was also similar within each ADA subgroup (ADA-positive and ADA-negative) between SB2 and INF (data not shown).

\section{DISCUSSION}

The results from this randomised, double-blind study demonstrate the equivalence of efficacy between SB2 and INF as well as the comparability in safety, immunogenicity and PK profiles. The results are comparable to the previous PLANETRA study, ${ }^{11}$ which also studied a biosimilar of infliximab in a similar setting.
The primary end point ACR20 has been compared in various ways to demonstrate the robustness of equivalence; the results uniformly exhibit the equivalence of ACR20 between SB2 and INF. In particular, our study has compared the efficacy end points at all visits, and has demonstrated the equivalence of ACR20 response over time, which is an advance over the data presented for the PLANETRA study. The comparability of efficacy end points over time has been suggested as an important criterion for biosimilarity, ${ }^{27}$ and our results are supportive in such manner. It is also notable to observe that other efficacy outcomes besides the ACR response such as DAS28, SDAI, CDAI and EULAR responses all show similarity between SB2 and INF, further supporting the biosimilarity of SB2 to INF. While results concerning SDAI and CDAI were post hoc analyses, as the components of these indices are all included within the components of ACR20 or DAS28, any bias due to post hoc specifications are expected to be minimal.

In terms of safety, SB2 has demonstrated a comparable safety profile to that of INF; in particular, the incidence of AEs associated with TNF inhibitors such as serious infections, TB, IRRs, malignancies and heart failure were comparable between SB2 and INF. The incidence rate of serious infections or TB was comparable to previous studies. ${ }^{28} 29$ It is notable that the incidence of TB was low (one case for each treatment group), which universal TB prophylaxis for patients with latent TB at screening might have contributed to. 
Table 2 Display of adverse events

\begin{tabular}{|c|c|c|}
\hline & $\begin{array}{l}\text { SB2 (N=290) } \\
\text { n (\%) }\end{array}$ & $\begin{array}{l}\text { INF }(\mathrm{N}=293) \\
\mathrm{n}(\%)\end{array}$ \\
\hline Any TEAEs, patients (\%) & $167(57.6)$ & $170(58.0)$ \\
\hline Latent tuberculosis & $17(5.9)$ & $20(6.8)$ \\
\hline Alanine aminotransferase increased & $23(7.9)$ & $8(2.7)$ \\
\hline Headache & $16(5.5)$ & $13(4.4)$ \\
\hline Nasopharyngitis & $14(4.8)$ & $15(5.1)$ \\
\hline Rheumatoid arthritis & $16(5.5)$ & $9(3.1)$ \\
\hline Aspartate aminotransferase increased & $12(4.1)$ & $8(2.7)$ \\
\hline Bronchitis & $9(3.1)$ & $11(3.8)$ \\
\hline Upper respiratory tract infection & $10(3.4)$ & $9(3.1)$ \\
\hline Back pain & $7(2.4)$ & $9(3.1)$ \\
\hline Arthralgia & $8(2.8)$ & $7(2.4)$ \\
\hline Pneumonia & $7(2.4)$ & $7(2.4)$ \\
\hline Hypertension & $6(2.1)$ & $8(2.7)$ \\
\hline Urinary tract infection & $7(2.4)$ & $5(1.7)$ \\
\hline Cough & $6(2.1)$ & $6(2.0)$ \\
\hline Rash & $6(2.1)$ & $5(1.7)$ \\
\hline Pharyngitis & $4(1.4)$ & $6(2.0)$ \\
\hline Pyrexia & $2(0.7)$ & $7(2.4)$ \\
\hline Dyspepsia & $1(0.3)$ & $6(2.0)$ \\
\hline Any SAEs & $26(9.0)$ & $26(8.9)$ \\
\hline Serious infections or tuberculosis & $9(3.1)$ & $6(2.0)$ \\
\hline Pneumonia & $3(1.0)$ & $2(0.7)$ \\
\hline Pneumonia bacterial & $1(0.3)$ & $0(0.0)$ \\
\hline Pyelonephritis & $1(0.3)$ & $0(0.0)$ \\
\hline Soft tissue infection & $1(0.3)$ & $0(0.0)$ \\
\hline Tuberculous pleurisy & $1(0.3)$ & $0(0.0)$ \\
\hline Urinary tract infection & $1(0.3)$ & $0(0.0)$ \\
\hline Enteritis & $1(0.3)$ & $0(0.0)$ \\
\hline Cellulitis & $0(0.0)$ & $1(0.3)$ \\
\hline Erysipelas & $0(0.0)$ & $1(0.3)$ \\
\hline Pulmonary tuberculosis & $0(0.0)$ & $1(0.3)$ \\
\hline Wound infection & $0(0.0)$ & $1(0.3)$ \\
\hline Infusion related reactions & $15(5.2)$ & $13(4.4)$ \\
\hline
\end{tabular}

TEAEs are listed for reported events of at least a frequency $\geq 2 \%$ in either study group in the safety population (SAF). Latent tuberculosis was reported when a positive Quantiferon test seroconversion occurred after randomisation. The incidence rate for any infections was 47 cases/100-person years for SB2 and 64 cases/100 person-years for INF.

INF, infliximab reference product; $S A E$, serious adverse event; TEAE, treatment-emergent adverse event.

The incidence of increased ALT levels was higher in SB2 than in INF (7.9\% vs $2.7 \%$, table 2 ), however, patients whose laboratory ALT values with an ALT of $3 \times$ ULN (upper limit of normal) and $5 \times \mathrm{ULN}$ were $5.2 \%$ and $1.4 \%$, respectively, for SB2, which are within the historically reported range of ALT abnormalities with INF $\left(2.5-9.5 \%\right.$ and $0.6-3.6 \%$, respectively). ${ }^{30}$

Immunogenicity was comparable between SB2 and INF; the incidence of $\mathrm{ADA}(\sim 50 \%)$ is higher than previous INF pivotal trials $^{4}$ but comparable with recent INF studies ${ }^{31} 32$ and PLANETRA ( 48\%), probably reflecting the advance of assay technology during the time. ${ }^{11}$ The apparent numerical difference was not statistically significant and efficacy was similar within each ADA subgroup (see online supplementary appendix S4-2), a pattern that was also observed in IRRs. The finding that efficacy is lower and the risk of IRRs is higher in ADA-positive patients is consistent with prior experience with infliximab. ${ }^{11} 31 \quad 32$ In ADA-positive patients we observed an approximately $40 \%$ higher rate of infusion reactions for SB2 compared with INF; however, among the ADA-negative patients, infusion reactions were twice as high for INF than SB2. The overall rate of infusion reactions was similar with $5.2 \%$ for SB2 and $4.4 \%$ for INF. Long-term observation will allow further insights into this important aspect. The PK results showed a comparable distribution of mean $\mathrm{C}_{\text {trough }}$ and variance to previous infliximab studies. ${ }^{411}$

As mentioned, biosimilars are hoped to decrease the economic burden in the treatment of RA. The issue of costeffectiveness of biologics ${ }^{5}$ may have to be addressed again with the advent of biosimilars, ${ }^{33}$ which could also have significant influence on local reimbursement policies.

While long-term efficacy and safety profiles and pharmacovigilance in the postmarket setting are important considerations ${ }^{7}$ and will have to be obtained, these are not within the scope of this report. However, to address these aspects at least in part, the main study is continuing with a 54-week end point for assessing long-term efficacy and safety including radiographic damage.

In conclusion, from the results of this randomised, doubleblind study, SB2 has demonstrated clinical equivalence to INF in terms of ACR2 0 at week 30; other efficacy end points also show consistently similar findings when compared with the originator product. The safety, immunogenicity and PK profiles are comparable between SB2 and INF.

\section{Author affiliations}

${ }^{1}$ Department of Internal Medicine, Catholic University of Daegu School of Medicine, Daegu, South Korea

${ }^{2}$ Clinical Center Banja Luka, Banja Luka, Bosnia and Herzegovina

${ }^{3}$ Medica Pro Familia, Gdynia, Poland

${ }^{4}$ MHAT "Dr. Ivan Seliminski", AD, Sliven, Bulgaria

${ }^{5}$ MEDICAL PLUS s.r.o, Uherske Hradiste, Czech Republic

${ }^{6}$ Lithuanian University of Health Sciences, Kaunas, Lithuania

${ }^{7}$ Internal Medicine \#1 Department, Ivano-Frankivsk National Medical University, Ivano-Frankivsk, Ukraine

${ }^{8}$ University Clinic Centre Sarajevo, Sarajevo, Bosnia and Herzegovina

${ }^{9}$ Poznanski Osrodek Medyczny NOVAMED, Poznan, Poland

${ }^{10}$ Institute of Rheumatology and First Faculty of Medicine, Charles University in Prague, Prague, Czech Republic

${ }^{11}$ MCBK S.C., Grodzisk Mazowiecki, Poland

${ }^{12}$ Medica Pro Familia Sp. z o.o. Spolka Komandytowo-Akcyjna, Warszawa, Poland

${ }^{13}$ Samsung Bioepis Co., Ltd., Incheon, Republic of Korea

${ }^{14}$ Medical University of Vienna, Vienna, Austria

Correction notice This article has been corrected since it was published Online First. Minor corrections have been made to the author affiliations, funding section and table 2 .

Acknowledgements The authors thank the patients who were involved in this study, the study personnel who made this work possible, and the study investigators: Bosnia and Herzegovina: Sokolovic S, Mekic M, Prodanovic N; Bulgaria: Dimitrov E, Geneva-Popova M, Mihaylova M, Staykov I, Toncheva A, Penev D, Oparanov B; Czech Republic: Dokoupilova E, Galatikova D, Ciferska H, Vitek P, Janska L; Korea, Republic of: Shim SC, Kang YM, Kim HA, Choe J-Y, Lee S-H, Bae S-C, Kim J, Kwok S-K, Lee YJ, Lee S-K; Latvia: Kadisa A, Mihailova A, Saulite-Kandevica D, Saleniece S; Lithuania: Milasiene R, Baranauskaite A, Arstikyte I, Basijokiene V; Philippines: Santos Estrella P, Hao L, Manapat-Reyes BH, Eullaran R; Poland: Porawska W, Kolczewska A, Stasiuk B, Janecka I, Grabowicz-Wasko B, Jedrychowicz-Rosiak K, Leszczynski P, Ruzga Z, Rychlewska-Hanczewska A, Hajduk-Kubacka S, Hilt J, Niebrzydowski J, Zielinska A; Romania: Berghea F, Popoviciu H, Mirea G, Pavel M, leremia G, Tanasescu C; Ukraine: Rekalov D, Zhdan V, Povoroznyuk V, Ignatenko G, Ter-Vartanian S, Vatutin M,

Stanislavchuk M, Gnylorybov A, Golovchenko O, Yatsyshyn R, Tseluyko V, Yagensky A, laremenko O, Shevchuk S; UK: Ong V, Mckay N, and the study team: Ilsun Hong (Samsung Bioepis).

Contributors JSS, JC and YHR contributed to study conception and design, acquisition of data, analysis and interpretation of data, drafting the manuscript and revising it critically for important intellectual content, and final approval of the version to be published. J-YC contributed to acquisition of data, analysis and interpretation of data, drafting the manuscript and revising it critically for important intellectual content, and final approval of the version to be published. NP, JN, IS, 
$E D, A B, R Y, M M, W P, H C, K J-R$ and $A Z$ contributed to acquisition of data, drafting of the manuscript and revising it critically for important intellectual content, and final approval of the version to be published. YHR wrote the paper on behalf of the sponsor. There were no professional writers or companies hired for this purpose. All coauthors contributed significantly to the writing of the manuscript.

Funding This study was funded by Samsung Bioepis Co., Ltd.

Competing interests $\mathrm{J}-\mathrm{YC}$ reports receiving grant/research support and consultant fees from Samsung Bioepis. JSS reports receiving grant/research support from AbbVie, Jassen, MSD, Pfizer, Roche, UCB, Consultant for: AbbVie, Amgen, AstraZeneca, Astro-Pharma, Celgene, GSK, Jassen, Lilly, Medimmune, MSD, Norvartis-Sandoz, Novo Nordisk, Pfizer, Roche, Samsung Bioepis, Sanofi, UCB. AB reports receiving grant/research support from AbbVie and Samsung Bioepis. NP, JN, IS, ED, RY, MM, WP, HC, KJ-R and AZ report receiving grant/research support from Samsung Bioepis. JC and YHR are employees of Samsung Bioepis.

Ethics approval Each national regulatory agency and central or local ethical committee.

Provenance and peer review Not commissioned; externally peer reviewed.

Open Access This is an Open Access article distributed in accordance with the Creative Commons Attribution Non Commercial (CC BY-NC 4.0) license, which permits others to distribute, remix, adapt, build upon this work non-commercially, and license their derivative works on different terms, provided the original work is properly cited and the use is non-commercial. See: http://creativecommons.org/ licenses/by-nc/4.0/

\section{REFERENCES}

1 Birnbaum H, Pike C, Kaufman R, et al. Societal cost of rheumatoid arthritis patients in the US. Curr Med Res Opin 2010;26:77-90.

2 Cross M, Smith E, Hoy D, et al. The global burden of rheumatoid arthritis: estimates from the global burden of disease 2010 study. Ann Rheum Dis 2014;73:1316-22.

3 Smolen JS, Landewe R, Breedveld FC, et al. EULAR recommendations for the management of rheumatoid arthritis with synthetic and biological disease-modifying antirheumatic drugs: 2013 update. Ann Rheum Dis 2014;73:492-509.

4 Maini R, St Clair EW, Breedveld F, et al. Infliximab (chimeric anti-tumour necrosis factor alpha monoclonal antibody) versus placebo in rheumatoid arthritis patients receiving concomitant methotrexate: a randomised phase III trial. ATTRACT Study Group. Lancet 1999;354:1932-9.

5 Modena V, Bianchi G, Roccatello D. Cost-effectiveness of biologic treatment for rheumatoid arthritis in clinical practice: an achievable target? Autoimmun Rev 2013; 12:835-8

6 EMA/CHMP. Guideline on similar biological medicinal products. 2015. http://www. ema.europa.eu/docs/en_GB/document library/Scientific guideline/2014/10/ WC500176768.pdf (accessed 6 Mar 2015).

7 Dorner T, Strand V, Castaneda-Hernandez G, et al. The role of biosimilars in the treatment of rheumatic diseases. Ann Rheum Dis 2013;72:322-8.

8 EMA/CHMP. Guideline on similar biological medicinal products containing biotechnology-derived proteins as active substance: non-clinical and clinical issues. 2014. http://www.ema.europa.eu/docs/en_GB/document_library/Scientific_guideline/ 2015/01/WC500180219.pdf (accessed 6 Mar 2015).

9 Jung SK, Lee KH, Jeon JW, et al. Physicochemical characterization of Remsima. MAbs 2014:6:1163-77.

10 Park W, Hrycaj P, Jeka S, et al. A randomised, double-blind, multicentre, parallel-group, prospective study comparing the pharmacokinetics, safety, and efficacy of CT-P13 and innovator infliximab in patients with ankylosing spondylitis: the PLANETAS study. Ann Rheum Dis 2013;72:1605-12.

11 Yoo DH, Hrycaj P, Miranda P, et al. A randomised, double-blind, parallel-group study to demonstrate equivalence in efficacy and safety of CT-P13 compared with innovator infliximab when coadministered with methotrexate in patients with active rheumatoid arthritis: the PLANETRA study. Ann Rheum Dis 2013;72:1613-20.

12 EMA/CHMP. CHMP summary of positive opinion for Remsima. 2013. http://www. ema.europa.eu/docs/en_GB/document_library/Summary_of_opinion_-_Initial_ authorisation/human/002576/WC500144832.pdf (accessed 6 Mar 2015).
13 Hirsch BR, Lyman GH. Biosimilars: a cure to the U.S. health care cost conundrum? Blood Rev 2014;28:263-8.

14 Shin DH, Kim Y, Kim YS, et al. A phase I pharmacokinetic study comparing SB2, an Infliximab biosimilar, and Infliximab Reference Product (Remicade(R)) in healthy subjects. Rome, Italy: EULAR Congress, SAT0144, 2015.

15 Anderson J, Caplan L, Yazdany J, et al. Rheumatoid arthritis disease activity measures: American College of Rheumatology recommendations for use in clinical practice. Arthritis Care Res (Hoboken) 2012;64:640-7.

16 Felson DT, Smolen JS, Wells G, et al. American College of Rheumatology/European League against Rheumatism provisional definition of remission in rheumatoid arthritis for clinical trials. Ann Rheum Dis 2011:70:404-13.

17 Shankar G, Arkin S, Cocea L, et al. Assessment and reporting of the clinical immunogenicity of therapeutic proteins and peptides-harmonized terminology and tactical recommendations. AAPS J 2014;16:658-73.

18 Abe T, Takeuchi T, Miyasaka N, et al. A multicenter, double-blind, randomized, placebo controlled trial of infliximab combined with low dose methotrexate in Japanese patients with rheumatoid arthritis. J Rheumatol 2006;33:37-44

19 Westhovens R, Yocum D, Han J, et al. The safety of infliximab, combined with background treatments, among patients with rheumatoid arthritis and various comorbidities: a large, randomized, placebo-controlled trial. Arthritis Rheum 2006:54:1075-86.

20 EMA/CHMP. Guideline on the choice of the non-inferiority margin. 2005. http:// www.ema.europa.eu/docs/en_GB/document_library/Scientific_guideline/2009/09/ WC500003636.pdf (accessed 6 Mar 2015)

21 US FDA. Guidance for Industry: non-inferiority clinical trials. 2010. http://www.fda. gov/downloads/Drugs/Guidances/UCM202140.pdf (accessed 6 Mar 2015).

22 International Conference on Harmonisation. Statistical Principles for Clinical Trials E9. 1998. http://www.ich.org/fileadmin/Public_Web_Site/ICH_Products/Guidelines/ Efficacy/E9/Step4/E9_Guideline.pdf (accessed 6 Mar 2015).

23 Koch GG, Tangen CM, Jung JW, et al. Issues for covariance analysis of dichotomous and ordered categorical data from randomized clinical trials and non-parametric strategies for addressing them. Stat Med 1998;17:1863-92.

24 Tangen CM, Koch GG. Complementary nonparametric analysis of covariance for logistic regression in a randomized clinical trial setting. J Biopharm Stat 1999;9:45-66.

25 Zink RC, Koch GG. SAS macro NParCov, version 2, non-parametric analysis of covariance. USA: Biometric Consulting Laboratory, Department of Biostatistics, University of North Carolina at Chapel Hill, 2002.

26 Reeve $R$, Pang $L$, Ferguson $B$, et al. Rheumatoid arthritis disease progression modeling. Ther Innov Regul Sci 2013;47:641-50.

27 Kay J, Smolen JS. Biosimilars to treat inflammatory arthritis: the challenge of proving identity. Ann Rheum Dis 2013;72:1589-93.

28 Curtis JR, Xi J, Patkar N, et al. Drug-specific and time-dependent risks of bacterial infection among patients with rheumatoid arthritis who were exposed to tumor necrosis factor alpha antagonists. Arthritis Rheum 2007;56:4226-7.

29 Galloway JB, Hyrich KL, Mercer LK, et al. Anti-TNF therapy is associated with an increased risk of serious infections in patients with rheumatoid arthritis especially in the first 6 months of treatment: updated results from the British Society for Rheumatology Biologics Register with special emphasis on risks in the elderly. Rheumatology (Oxford) 2011;50:124-31.

30 EMA. Remicade: EPAR—Product Information (SmPC). 2014. http://www.ema. europa.eu/docs/en_GB/document_library/EPAR_-_Product_Information/human/ 000240/WC500050888.pdf (accessed 6 Mar 2015).

31 Krintel SB, Grunert VP, Hetland ML, et al. The frequency of anti-infliximab antibodies in patients with rheumatoid arthritis treated in routine care and the associations with adverse drug reactions and treatment failure. Rheumatology (Oxford) 2013;52:1245-53.

32 Wolbink GJ, Vis $M$, Lems W, et al. Development of antiinfliximab antibodies and relationship to clinical response in patients with rheumatoid arthritis. Arthritis Rheum 2006:54:711-15.

33 Brodszky V, Baji P, Balogh 0, et al. Budget impact analysis of biosimilar infliximab (CT-P13) for the treatment of rheumatoid arthritis in six Central and Eastern European countries. Eur J Health Econ 2014;15(Suppl 1):S65-71. 